\title{
Comunicação Educativa: perspectivas e desafios com a COVID-19
}

Joaquim José Jacinto Escola'

'Universidade de Trás-os-Montes e Alto Douro, Porto - Portugal

RESUMO - Comunicação Educativa: perspectivas e desafios com a COVID-19. A reflexão sobre a comunicação educativa instiga-nos a refletir sobre a importância da comunicação humana e das mediações tecnológicas na educação. A situação pandémica que atinge o mundo colocou-nos um conjunto de desafios sem paralelo. A história da comunicação, (Cloutier, 2001) bem como a periodização das tecnologias na educação (Costa, 2007) comprovam uma estreita relação entre os tipos de comunicação, os dispositivos utilizados, e as respostas disponibilizadas pela comunicação educativa em face dos desafios que a COVID-19 colocou, tendo como pano de fundo o contexto de ensino português.

Palavras-chave: Comunicação Educativa. Tecnologia Educativa. Sociedade do Conhecimento. Tecnologias da Informação e Comunicação. COVID-19.

ABSTRACT - Educational Communication: perspectives and challenges with COVID-19. The reflection on educational communication encourages us to reflect on the importance of communication and technological mediations in education. The pandemic situation that affects the world has presented us with an unparalleled set of challenges. The history of communication (Cloutier, 2001) as well as the periodization of Technologies in education (Costa, 2007) prove a close relationship between the types of communication, the devices used, and the responses made available by educational that the COVID-19 put it, against the backdrop of the portuguese teaching context.

Keywords: Educational Communication. Educational Technology. Knowledge Society. Information and Communication Technology. COVID-19. 


\section{Introdução}

Sociedade pós-moderna (Lyotard, 1987, 1989), Sociedade Transparente (Vattimo, 1991), Sociedade da Informação e Comunicação, Sociedade informacional, Sociedade em Rede (Castells, 1989), sociedade do conhecimento, Telepolis (Echeverria, 1994), Tecnopolis (Postman, 1994) são algumas da inúmeras propostas que têm emergido, num momento ou outro, para caracterizar o tempo em que vivemos. Creio que a multiplicidade das designações atesta a complexidade do tempo e a manifesta dificuldade de encontrar um elemento que seja verdadeiramente agregador. Em todas elas permanecem dimensões que são comuns e que nos permitem identificar o que é deveras essencial no tempo em que vivemos. Conscientes de que o projeto da modernidade não se cumpriu, apesar de um dos mais reconhecidos arautos da pós-modernidade (Lyotard, 1987, 1989) terem pretendido avançar para um tempo que se pretende novo.

Vivemos num mundo avassalado por uma massa assustadora de informação que chega a qualquer um através de múltiplas fontes de informação e de forma ininterrupta. O desenvolvimento tecnológico trouxe consigo um inaudito progresso nos dispositivos tecnológicos que vão conquistando um lugar fundamental nos processos de mediação comunicacional. A proposta de leitura da história da comunicação com que nos brindou Jean Cloutier, em dois momentos fundamentais, ainda que distanciados quase três décadas no tempo, continua a ser decisiva para a compreensão do papel da comunicação educativa. A Era de EMEREC ou a Comunicação Audio-scripto-visual na hora dos self-media (1979) e Petit traité de communication. EMEREC à l'heure des technologies numeriques (2001) são, por isso mesmo, duas obras fundamentais para a compreensão da relação entre a comunicação, as mediações tecnológicas e o vasto território da educação.

Neste artigo, somos desafiados a pensar o lugar da comunicação educativa numa tripla dimensão. Conceptualização do conceito de comunicação educativa, discussão em torno da relevância crescente das mediações tecnológicas no processo de ensino e aprendizagem e, por fim, os desafios que a pandemia do COVID-19 trouxe à comunicação educativa no contexto português.

\section{A Comunicação Educativa}

Cada vez é mais evidente o lugar que a comunicação detém na contemporaneidade. É-nos dado observar a gradual consolidação da sociedade da informação e da comunicação, enterrando definitivamente as decadentes sociedades industriais. A própria designação de pósindustrial (Bell, 1976), pós-moderna (Lyotard, 1987, 1989), atesta a mudança paradigmática em que a matéria prima passa a ser a informação.

A palavra comunicação tem a sua origem no adjectivo latino communis, com o sentido de posse em comum de algo por vários indivíduos. É frequente encontrarmos nos dicionários o vocábulo associado às 
ideias de união que se pode construir entre espaços físicos como são os passeios, escadas, ruas, canais, ou outros, ou num universo humano a afinidade no trato e relação entre duas pessoas.

É no espaço da reflexão antropológica de cariz filosófica que buscamos e encontramos verdadeiramente uma fundamentação adequada à compreensão da comunicação educativa. A filosofia contemporânea, pelo menos alguns dos mais significativos movimentos, distinguiu-se por uma recusa muito clara de um pensamento herdeiro da modernidade, nutrido de um gélido racionalismo que eleva e absolutiza a categoria de sujeito autocentrado, auto-suficiente, egologicamente construído e legitimado num crescente deserto de seres atomizados e isolados. $\mathrm{O}$ pensamento cartesiano consagra um lugar fulcral ao sujeito (subjectum), o cogito, enquanto ser racional, ser pensante, garante da verdade de todos os raciocínios. Prisioneiro desta perspectiva poderíamos considerar, de uma forma global, que a concepção tradicional de educação tendeu a privilegiar nos processos comunicacionais, a educação como processo unidirecional, centrada na principal ou quase exclusiva fonte de informação, o professor e, nesta medida sem possibilidade de retorno e ajustamento das mensagens.

O que é a comunicação educativa? Partamos da definição que Paciano Fermoso (1985, p. 275) na sua Teoria de la Educación considerou que

A comunicação educativa é uma comunicação qualificada, na que a participação, a doação e as demais caraterísticas são específicas e especialmente aplicadas. Há muito outros tipos de comunicação, mas singulariza-se entre todas é a comunicação educativa.

A tese essencial de Paciano Fermoso (1985) é a de que apesar de nos confrontarmos com uma multiplicidade de tipos de comunicação, a comunicação educativa revela uma especificidade muito própria, que a individualiza e distingue das demais formas de comunicação. Ao conceder uma atenção à especificidade da comunicação educativa Paciano Fermoso põe o foco muito mais no que a distingue do que o que a aproxima da comunicação de uma forma global. Neste sentido seria legítimo considerar a comunicação educativa como um capítulo da comunicação em geral. Numa análise mais atenta, o autor chama a atenção para duas das características mais evidentes da mesma: as noções de participação e doação.

Partindo da etimologia da palavra comunicação sobressaem, de forma evidente, os sentidos de comunicar, participar, comungar, nos quais detetamos uma referência comum à ideia de comunidade ou de posse de algo em comum. Na noção de comunicação está presumida a unidade ou comunidade entre as pessoas que comunicam. Emílio Redondo (1999, p. 163), definirá a comunicação como a

[...] relação real estabelecida entre dois - ou mais seres em virtude da qual um deles participa do outro, ou ambos participam entre si; ou também relação real estabelecida 
entre dois ou mais seres em virtude do qual se põem em contato, e um deles - ou ambos - fazem doação de algo a outro (Redondo, 1999, p. 178).

Creio, neste sentido, que estas duas marcas distintivas, ainda que sejam fundamentais para a comunicação educativa, encontram-se presentes na origem da noção de comunicação. O regresso à matriz mais original da comunicação educativa reforça a continuidade entre o sentido originário da noção de comunicação e a estreita relação daquela com a noção de educação. Esta última tem também inscrita a dimensão da dádiva, sobretudo se atendermos ao sentido mais original da ação de educar como alimentar, criar, amamentar ou mesmo nutrir. O modelo maternal a que se liga a educação não pode ser esquecido num processo em que a mãe disponibiliza à criança o alimento, nutre-a com o que há de mais importante à manutenção do seu bem estar. Alimentar é garantir as condições essenciais à sobrevivência física daquele a quem se disponibiliza o nutriente essencial. Se a dimensão física da dádiva se encontra presente na noção de amamentar, ao longo dos séculos, no curso da evolução da noção de educação é-nos dado assistir a uma transmutação da dimensão física do alimento para a dimensão espiritual. A noção de aluno, conserva ainda, na sua raiz etimológica, a ideia de alimentação. Etimologicamente o aluno (alumnum) é aquele que é alimentado. A educação é também dádiva se for tomada no sentido de tirar de dentro para fora, na medida em que se procura, através do esforço educativo do professor, encontrar no outro o melhor que tem em si. Investir o melhor de nós, enquanto educadores, para que o aluno deixe brotar de dentro de si, o que potencialmente aguarda uma oportunidade para se desvelar. Se o movimento de retirar de dentro para fora emerge como oposto ao alimentar, lido tantas vezes como acção de colocar dentro, de colmatar um vazio, de preencher, não deixa de conservar a ideia de que ação do professor, do educador é de disponibilizar na própria praxis o melhor de si para assegurar que do interior do educando brote, por sua vez, o melhor de si. O terceiro sentido, a educação como condução conserva a noção de dádiva e, ao mesmo tempo, de participação. A metáfora da viagem que se inscreve na ação de guiar, de conduzir, impõe ao professor e ao alunos, viajantes embarcados na mesma viagem da construção do conhecimento, o desafio superior de percorrerem os caminhos, de assumirem os riscos inerentes à viagem, de participarem conjuntamente na identificação das vias, veredas no curso das quais se foram desenhando as rotas mais instigantes do conhecimento. Os três sentidos associados à noção etimológica de educação conservam estas dimensões de dádiva e participação aproximando do conceito de comunicação.

Todo o processo educativo não pode ser concebido desvinculado do universo comunicativo, sob pena de desvirtuar o que é essencial na educação. Neste sentido a tese central é a de que educação e comunicação constituem dois pólos indissociáveis. Se é possível admitir que pode haver comunicação sem educação, a inversa não nos parece verdadeira. Nessa medida, à imagem da pragmática da comunicação de (Watzlawick; Beavin; Jackson, 1967), defendemos que o primeiro grande axioma 
da comunicação educativa é a de que não não há educação sem comunicação.

Assim o postulado de que não há educação sem comunicação impõe-se como condição primeira, premissa irrefutável de toda a autêntica comunicação educativa. A afirmação deverá continuar a manifestar a pretensão de validade mesmo quando confrontada com as mediações que vão pontuando as criações mais recentes do universo tecnocientífico. Sujeitar-se a este critério de validade significa procurar responder a um esforço de legitimação da acção pedagógica como acção comunicativa. Numa leitura atenta da história da educação percebemos com facilidade que nem sempre a educação esteve associada à uma autêntica comunicação. A exclusiva preocupação com a transmissão de um conjunto de conteúdos ou informações não esgota a essência da comunicação pois tal posição está ainda impregnada de uma perspectiva egocêntrica incapaz de se abrir a um heterocentrismo, condição indispensável e, por isso mesmo, fundamental para a construção de uma educação autêntica.

O segundo axioma da comunicação educativa estabelece que Existir e Educar têm a mesma extensão, evidenciando o paralelismo entre a existência humana e a de educação.

Se existir é estar fora, estar no mundo, ser em situação, ser no mundo com outros, quer a educação, quer a existência acontecem entre o nascimento e a morte. O sentido da educação como viagem, como caminho, explorado anteriormente, mostra que o sujeito concretiza o seu projeto vital em relação próxima com o mundo e com os outros, liga-se à condição antropológica do ser humano como ser inacabado, insatisfeito, não concluído. Paulo Freire, em vários textos lembrou a importância do inacabamento para a compreensão do necessidade da comunicação e do diálogo. Na Pedagogia do Oprimido escreve Freire (2007):

A concepção e práticas 'bancárias', imobilistas, 'fixistas', terminam por desconhecer os homens como seres históricos, enquanto a problematizadora parte exatamente do caráter histórico e da historicidade dos homens. Por isso mesmo é que os reconhece como seres que estão sendo, como seres inacabados, inconclusos, em e com uma realidade que, sendo histórica, também é igualmente inacabada. Na verdade, diferentemente dos outros animais, que são apenas inacabados, mas não são históricos, os homens se sabem inacabados. Têm consciência da inconclusão. Aí se mostram as raízes da educação mesma, como manifestação exclusivamente humana. Isto é, na inconclusão dos homens e na consciência que dela têm. Permanente, na razão da inconclusão dos homens e do devir da realidade (Freire, 2007, p. 84).

As noções de educação permanente e de aprendizagem ao longo da vida, especialmente a última, pontuam cada vez mais os discursos oficiais, mostrando que a complexidade e a evolução da civilização impõem a necessidade de formação ao longo da vida. Estas reforçam a 
convergência entre as noções de educação e existência, a relação entre a condição de inconclusão do ser humano e a imperiosa necessidade de educação.

O terceiro axioma defende que na comunicação educativa a comunicação objetiva potencia a passagem para a comunicação intersubjetiva.

Podemos aceitar que em inúmeros momentos da história da educação a tendência foi para acentuar a dimensão objectiva da comunicação, sendo a tónica colocada muito mais na transmissão da informação do que na criação de condições para a eclosão de uma "[...] comunicação com comunhão” (Marcel, 1950, p. 221), signo de uma verdadeira comunicação intersubjectiva. Discutindo a noção de presença Gabriel Marcel estabelece a distinção entre as duas formas de comunicação (objetiva e subjetiva), que são de capital importância para a compreensão na comunicação educativa:

Podemos sentir com muita intensidade que alguém que está no mesmo quarto que nós, alguém a quem vemos, ouvimos e podemos tocar, não está, apesar de tudo, presente. Que se encontra infinitamente mais longe de nós do que aquele que amamos e que se encontra a milhares de kilómetros [...]. Que presença é esta que falta aqui? Não seria correto dizer que não conseguimos comunicar com o indivíduo que se encontra ao nosso lado. Ele não é nem surdo, nem cego, nem imbecil. Entre nós uma determinada comunicação material foi assegurada, mas somente material, em tudo semelhante à comunicação estabelecida entre dois postes distintos, um emissor e outro receptor. O essencial falta apesar de tudo. Poder-se-ia dizer que é uma comunicação sem comunhão (Marcel, 1950, p. 221).

Esta distinção entre a comunicação objetiva e comunicação intersubjetiva realizada por Jaspers (1989), coloca-se na mesma linha da distinção proposta por Marcel da comunicação com comunhão e sem comunhão. A comunicação educativa não rejeita a dimensão instrutiva, objetiva, mais centrada nos conteúdos, e que designamos por comunicação objetiva. No entanto, a chave está na capacidade do professor ser capaz de garantir a transição entre a comunicação sem comunhão para uma comunicação com comunhão, respeitando sempre o outro na sua identidade, reconhecendo sempre a pessoa que habita no aluno.

A concepção freiriana de educação, ao instituir de forma tão radicalmente dicotómica a distinção entre a educação bancária da educação dialógica associa, de modo inequívoco, numa relação profunda as noções de educação e comunicação, transferindo para a segunda a primazia, e, não escondendo a predileção que a mesma desde sempre exerceu sobre si. Escreve o eminente pensador brasileiro:

Analisemos, ainda que brevemente, essas duas posições educativas: uma, que respeita o homem como 'pessoa'; outra, que o transforma em 'coisa'.

Iniciemos a apresentação e crítica da segunda concepção em alguns dos seus pressupostos. 
Daqui por diante, essa visão chamaremos de concepção 'bancária' da educação, pois ela faz do processo educativo um ato permanente de depositar conteúdos. Ato no qual o depositante é o 'educador' e o depositário o 'educando'.

A concepção bancária - ao não superar a contradição educador-educando, mas, pelo contrário, ao enfatizá-lo, não pode servir senão à 'domesticação' do homem.

Da não superação dessa contradição, decorre:

a) que o educador é sempre quem educa; que o educando, o que é educado;

b) que o educador é quem disciplina; o educando, o disciplinado;

c) que o educador é quem fala; o educando, o que escuta;

d) que o educador prescreve; o educando segue a prescrição;

e) que o educador escolhe o conteúdo dos programas; o educando o recebe em forma de 'depósito';

f) que o educador é sempre quem sabe; o educando, o que não sabe;

g) que o educador é o sujeito do processo; o educando seu objeto (Freire, 1974, p. 14-15).

Com legitimidade, poder-se-ia defender, partindo da própria designação de educação dialógica, que Paulo Freire recorda o lugar incontornável do diálogo e da comunicação em todo o processo educativo. Inspirando-se em Jaspers discute a centralidade do diálogo e ao mesmo tempo que denuncia o anti-diálogo (Freire, 1984, p. 106-108). Para reforçar esta dimensão, referindo-se ainda do pensamento de Karl Jaspers, escreve na obra Educação e Mudança (1979, p. 28): “Jaspers disse: 'Eu sou na medida em que os outros são.' O homem não é uma ilha. É comunicação. Logo, há uma estreita relação entre comunhão e busca”.

Na obra Extensão e Comunicação, Freire (1988) aprofunda a questão ao declarar que

Não há, realmente, pensamento isolado, na medida em que não há homem isolado.

Todo o ato de pensar exige um sujeito que pensa, um objeto pensado, que mediatiza o primeiro sujeito do segundo, e a comunicação entre ambos, que se dá através de signos linguísticos. O mundo humano é, desta forma, um mundo de comunicação.

Corpo consciente (consciência intencionada ao mundo, à realidade), o homem atua, pensa e fala sobre esta realidade, que é a mediação entre ele e os outros homens que também atuam , pensam e falam (Freire, 1988, p. 66).

A comunicação educativa filia-se na concepção dialógica da educação, inspirando-se no pensamento de Freire (2007), mas também na dialógica de Buber (2014), na filosofia existencial de Marcel (1927, 1950) e Jaspers (1989), no personalismo de Mounier (2010). Desta forma, muito mais importante do que considerar a educação a partir de um ângulo que teve na oposição/relação Sujeito - Objecto o paradigma, importa ir para além deste modelo. Também o pólo Sujeito - Sujeito não responde 
cabalmente à especificidade do fenómeno comunicacional no espaço educativo. Se o pólo Sujeito - Sujeito consegue evitar o perigo da redução do aluno à condição de objecto, a coisificação (Sartre) do aluno, dimensão pouco respeitosa da humanidade do homem, não assegura por si só, a marca da relação inscrita na condição humana. A modernidade, na linha e inspiração cartesiana, ao outorgar ao sujeito a condição de auto-suficiência tendeu a desvalorizar as dimensões da relação e comunicação.

A comunicação educativa, combinando a comunicação sem comunhão com a comunicação com comunhão, estabelece níveis de intensidade relacional e comunicacional que têm nos pólos $e u-t u$ ou $e u$ - ele, eu - isso ou ainda o nós, o contexto de discussão acerca de reconhecimento da alteridade da conversão do outro em interlocutor válido. A comunicação educativa recusa liminarmente a relação $e u$-isso, por considerar que o aluno, em nenhuma situação, pode ser pensado como objeto, e muito menos reduzido à condição de coisa. Ainda que a relação que se estabelece inicialmente entre educador e educando se apresente como uma relação eu-ele, o conhecimento crescente entre ambos, a simpatia experimentada, o respeito e reconhecimento, permitirão a passagem para a uma relação $e u$-tu, e o nós. A comunicação interpessoal desempenha, por isso mesmo, na relação aluno-professor, aluno-aluno um papel fundamental, pois é aí, na busca conjunta do conhecimento, que o verdadeiro encontro entre ambos se dá. O envolvimento de ambos, a participação ativa e cooperante do professor e aluno na viagem em direção ao conhecimento criam as condições para o reconhecimento pelo outro dando-se neste campo o encontro entre ambos.

O quarto axioma reconhece que os meios e recursos de ensino e, de forma muito especial, os recursos digitais podem ter um papel muito relevante como mediações nos processos de comunicação e como facilitadores na construção do conhecimento.

Nos últimos dois séculos, a problemática da comunicação educativa tem que ser pensada numa maior proximidade com o universo técnico e tecnológico, refletindo crítica e criteriosamente sobre os instrumentos saídos do progresso tecnocientífico. Toda a história da educação identifica a presença de mediações, de que os professores se serviram no processo de comunicação. O livro foi, indiscutivelmente, o meio e recurso que durante mais tempo se destacou como apoio ao ensino desde a escola elementar ao ensino superior. O livro de texto, manual escolar, continua a desempenhar um incontornável papel nas escolas, mesmo que hoje apareça como manual digital. A invenção da imprensa com carateres móveis por Gutenberg, potencializa a utilização do livro nos contextos educativos. Mais próximo de nós, em termos temporais, séculos XIX e XX, a escola assistiu à invenção de dispositivos que apesar de emergirem em contextos completamente exteriores a si, paulatinamente foram sendo integrados pelos professores nos processos e estratégias de comunicação educativa. A fotografia, o cinema, o rádio, a televisão, mais recentemente, a web tornaram-se presença regular nas escolas como meios e recursos de apoio ao ensino, garan- 
tindo ao professor a possibilidade de explicitar e concretizar melhor as temáticas, ultrapassar um certo verbalismo e modelos unidirecionais de comunicação. Mas é com o desenvolvimento das Tecnologias da Informação e Comunicação, com a influência da informática, tecnologia vídeo e telemática que mais se acentua a presença da tecnologia como suporte na comunicação educativa.

A utilização massiva da tecnologia pelos cidadãos tem consequências na organização da sociedade, mas também na escola. A história da tecnologia educativa atesta esta estreita relação entre a invenção de dispositivos tecnológicos, o uso generalizado na sociedade e a integração posterior daqueles na prática docente. Esta história confirma duas tendências: a estreita relação entre a invenção dos dispositivos e a sua rápida integração na prática dos professores e o sentimento de receio em relação à possibilidade dos dispositivos conquistarem um lugar incontornável capaz de conduzir à supressão dos professores. A primeira tendência é facilmente confirmada numa análise da periodização da evolução das tecnologias na educação (Costa, 2007). A segunda é comprovada por registos que foram sendo conservados ao longo do tempo. Em relação à segunda tendência, Neil Postman (2002, p. 68) na obra $O$ Fim da Educação. Redefinindo os valores da Escola e Larry Cuban (1986, p. 5) na obra Teachers and Machines: the classroom use of the technology since 1920 deixam-nos um poema escrito na década de 20 do século passado por um professor, onde se testemunha o medo provocado pelo sucesso e pela novidade das invenções tecnológicas mais recentes.

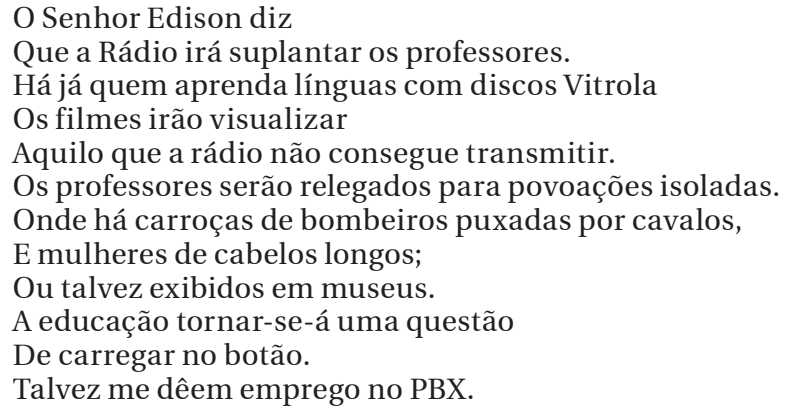

Dispensar atenção ao quadro evolutivo das tecnologias na educação ajuda a compreender a dinâmica da criação tecnológica e a integração na sala de aula. A comunicação educativa incorpora as ferramentas tecnológicas, explorando sempre as possibilidades didáticas dos mesmos. Tomando como referência a proposta de Costa (2007), que se inspira na cronologia da Association for Education Communications and Technology, a periodização das tecnologias na Educação realiza-se em seis períodos. O primeiro período decorre entre 1923 e 1931. Neste, destaca-se a presença de materiais visuais e a sua integração na prática docente. A opção pelos materiais audiovisuais era feita com o objetivo de apoiar, na visualização e concretização das ideias, bem como na explicitação dos conceitos. Estes suportes audiovisuais, paulatinamente 
Comunicação Educativa

integrados no ensino pelos professores, passam a ser vistos como ajuda ao trabalho docente. Neste primeiro momento, destacam-se dois meios de comunicação de massa: o rádio e o cinema mudo. As influências teóricas encontram-se vinculadas aos estudos sobre comportamento animal e humano, tendo em Thorndike, a fonte e, ao mesmo tempo, inspiração em termos de teorias de aprendizagem (conexionismo e associacionismo).

O segundo período desenvolve-se entre 1932 e 1945, e corresponde ao que Costa (2007, p. 18-19) designou por período da consolidação. Assistimos à criação de dispositivos de ensino que mereceram o reconhecimento na comunidade educativa pelo êxito que alcançaram enquanto suporte de comunicação durante a preparação dos contingentes militares que iriam para o combate na Segunda Grande Guerra. Os constrangimentos provocados pela necessidade de preparar um número tão elevado de soldados, com um grupo reduzido de formadores, num período de tempo tão curto, levam a uma maior atenção aos recursos de ensino. A criação do retroprojetor, primeiro meio e recurso especialmente concebido para o ensino, vai marcar durante décadas as estratégias de comunicação em vários níveis de ensino, abandonando o contexto original de criação, isto é, a preparação de militares, e invadindo as salas de aula. Este período é também marcado pelo desenvolvimento de materiais para o ensino, com destaque para a televisão educativa, e, simultaneamente, pela formação de profissionais e professores para a elaboração de materiais de suporte à transmissão da informação. Alguns estudos na área da psicologia vão investigar as problemáticas da relação entre a percepção e a memória, a quantidade de informação retida em função de cada um dos sentidos ou da combinação entre estes. Destas investigações saem resultados que apoiarão teorias de aprendizagem que buscam fundamentar as opções do audiovisual nos processos de ensino e aprendizagem.

O terceiro período, designado por período da grande expansão (Costa, 2007, p. 20-22), tem início em 1946, logo após o terminus da Segunda Grande Guerra e estende-se até o ano de 1957, marcando definitivamente a génese da Tecnologia Educativa. A influência da Psicologia, particularmente a partir do comportamentalismo, faz com que a proposta de Skinner, seja considerada historicamente como marco para a resolução de problemas no domínio de comunicação através de novos meios. Ele envolve outras áreas de conhecimento, trazendo para o centro da discussão das questões didáticas o contributo de cada uma destas fontes, imprimindo um caráter muito especial à tecnologia educativa. Os artigos de Skinner (1954) The Science of Learning and the Art of Teacnhing publicado em 1954, e Teaching Machines, publicado em outubro de 1958, na revista Science, compilados em livro mais tarde (Skinner, 1969), proclamam uma revolução científica no ensino e, simultaneamente, fazem a apologia das máquinas de ensinar, da automatização do ensino, evolução que teria como corolário lógico a supressão do professor. Estes dois artigos assinalam o nascimento oficial da Tecnologia Educativa. 
Entre 1958 e 1970 decorre o período que Costa (2007, p. 20-22) apelida de grande expansão. Objetivamente assiste-se a um progresso muito importante no domínio das tecnologias. O desenvolvimento do programa espacial russo que culmina com o lançamento em finais de 1957 do primeiro satélite, o Sputnik, gera pânico nos dirigentes dos EUA. Como resposta, os Estados Unidos aceleraram o desenvolvimento tecnológico em todo país, por forma a competir com o seu principal inimigo. Aumentam o financiamento para investir na criação de conteúdos e modificações curriculares em Universidades e escolas (curriculum packages), em articulação com iniciativas que visavam apetrechar as instituições educativas com as mais modernas tecnologias e materiais. A influência da Teoria Matemática da Informação (Shannon; Weaver, 1948) e de outros teóricos da comunicação e da Teoria dos Sistemas (Bertalanffy, 1986) são decisivas para a expansão da tecnologia na educação.

O quinto período tem como baliza temporal os anos de 1971 e 1982 e é caracterizado como sendo o da reafirmação e abertura (Costa, 2007, p. 22-24). O desenvolvimento da tecnologia informática traz para o interior das intuições educativas o computador, o dispositivo que conquistará um lugar central na área da tecnologia educativa. Realizam-se experiências pedagógicas para se explorar as possibilidades de utilização do computador como recurso de ensino. Do ponto de vista da investigação, definem-se claramente duas linhas: uma que já vem do período anterior, "[...] uma concepção de tecnologia educativa que subordina a investigação sobre os processos de aprendizagem ao material utilizado. A outra, que se encontra intimamente ligado à análise da influência que os materiais e os dispositivos têm sobre as modalidades de aprendizagens" (Costa, 2007, p. 22-23). A definição de tecnologia educativa proposta pela Association for Education Communications and Technology (AECT, 2001), em 1972, vem pôr em evidência a orientação sistemática, proporcionando uma visão integrada, sistémica e racional no sentido de resolver problemas de ensino e aprendizagem. Educational Technology é definida como "[...] a field involved in facilitation of humain learning through the systematic identification, development, organization and utilization of a full range of learning resources and througt the management of these processes". A tecnologia educativa, durante este período, evidencia o diálogo interdisciplinar, o contributo de várias áreas de conhecimento (ciências da comunicação, psicologia, sociologia, informática, entre outras) que lhe concedem o fundamento para a legitimar a intervenção na resolução dos problemas do ensino e aprendizagem.

O último período decorre entre 1983 e 1999, o período determinado pelo computador (Costa, 2007, p. 24-28). Naquele exploram-se as possibilidades de inovação de que as Tecnologias da Informação e Comunicação dispõem. A informática, a tecnologia vídeo, a telemática ou a robótica passam a ter um papel de grande relevância na educação. O interesse de investigação dos meios analógicos transfere-se gradualmente para os meios digitais. Costa (2007, p. 24) identifica dois momentos 
dentro desse período e que exigem uma diferenciação quanto ao grau de desenvolvimento tecnológico: o primeiro mais ligado à multimédia, e que caracteriza a década de 90, e o segundo, que coincide com o início do novo milénio, mais centrado nas possibilidades que o acesso à internet abre, mais especificamente as possibilidades que a World Wide Web oferece. A figura que abaixo apresentamos mostra a evolução das tecnologias na educação.

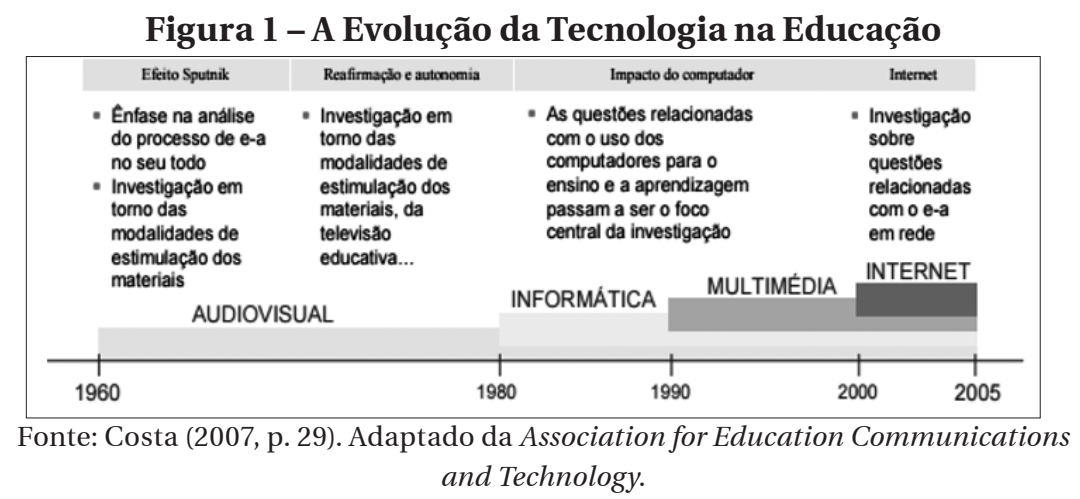

Como rapidamente se percebe desta breve incursão na história da Tecnologia Educativa, criação tecnológica, decorrente do progresso científico e tecnológico, conquista uma especial relevância em momentos diferenciados e os seus reflexos são evidentes na sociedade. A influência e presença da tecnologia no espaço mediático e na sociedade de uma forma geral repercutir-se-á na escola. Na Sociedade da Informação e Comunicação, a comunicação educativa comprova de modo evidente a entrada de determinada tecnologia na escola e o modo como foram sendo utilizados os recursos tecnológicos.

Uma das marcas decisivas da sociedade da informação e comunicação radica na descentração da escola como foco principal de conservação do vasto património de saber acumulado ao longo de séculos. A comunicação objetiva do professor é amplamente apoiada por fontes diferenciadas. A presença constante dessas fontes, disponibilizando informação, alarga significativamente a quantidade de informação a que cada indivíduo pode aceder. No entanto, tal situação é vista como podendo arrastar consigo a uma diminuição evidente do prestígio da própria escola. Se o aluno pode encontrar a informação relevante de que necessita fora da instituição escola, se a mesma se apresenta codificada através de linguagens mais próximas do seu interesse e mais fáceis de descodificar, e se as mensagens assim organizadas chegam mais facilmente ao estudante, o próprio prestígio do professor seria de algum modo atingido. Contudo, a situação de pandemia teve o privilégio de por em evidência que o papel do professor saiu reforçado, apesar do reforço da utilização dos recursos de EaD, destacando-se como guia e mediador do conhecimento. 


\section{Desafios à Comunicação Educativa no Período de Pandemia e Pós-Pandemia}

O contexto em que se desenvolveu a pandemia trouxe um conjunto muito significativo de desafios à comunicação educativa. O primeiro grande desafio prende-se, de forma inequívoca, com a manutenção da concepção cumulativa da comunicação no quadro da sua evolução proposto por Cloutier $(1975 ; 2001)$. A ideia de que cada episódio na história da comunicação alarga as possibilidades que o episódio anterior consagrou (2001, p. 1), esbarra, no atual contexto, com uma dificuldade premente que é a crescente mediatização da comunicação que se serve exclusivamente de dispositivos tecnológicos nos processos de comunicação educativa, diminuindo grandemente o lugar da palavra dita. A tese de que cada novo episódio acrescenta novos meios aos antigos sem os eliminar encontra no contexto pandémico dificuldades evidentes. Os quinto e sexto episódios da história da comunicação de Cloutier (2001), a comunicação comunitária e a comunicação planetária, respetivamente, não eliminaram a comunicação interpessoal, mas a decisão do confinamento da população portuguesa e o encerramento físico das escolas, bem como a ausência de atividades presenciais diminuiu dramaticamente as possibilidades de uma comunicação integral, no sentido de permitir que o ser humano esteja completamente como ser de comunicação, ser situado, encarnado, numa palavra como ser de relação. A opção pela continuidade das atividades letivas, recorrendo a plataformas de ensino a distância, numa combinação entre a comunicação síncrona e a assíncrona, foi muito importante não só porque permitiu a continuidade da relação entre os professores e os alunos, mas também porque, recorrendo aos dispositivos tecnológicos, conseguiu assegurar um contexto seguro de aprendizagem dos estudantes e, ao mesmo tempo, transpor os constrangimentos espaciais e temporais com que a comunidade educativa se confrontava.

$\mathrm{O}$ momento que vivemos convida-nos a regressar ainda à periodização de comunicação em Cloutier, para se constatar que o ponto de desenvolvimento a que chegámos celebra a concretização do desejo antigo do homo communicans de fazer chegar mais longe as suas mensagens e conseguir que as mesmas se inscrevessem em suportes que lhes permitissem a sua conservação no tempo. Como defende Cloutier (2001) a partir do segundo episódio da comunicação, a comunicação de elite, e que teve início com a invenção da escrita, começa-se paulatinamente a responder às dificuldades temporais, inventando-se tecnologias que podem conservar as mensagens para além da existência dos sujeitos que as produziram. A durabilidade das mensagens necessita apenas de encontrar suportes em que as mesmas possam ser gravadas. Por um lado cada indivíduo consegue fazer chegar mais longe as suas mensagens, tem condições de as ver perpetuar/conservar para além da sua existência e duração, no entanto, uma parte significativa do valor da comunicação no seu primeiro episódio (comunicação interpessoal), em que o medium, o meio privilegiado é o corpo, esbate-se na imagem 
ou numa representação virtual do mesmo no ciberespaço. Não é a totalidade do corpo, não são todos os sentidos que se relacionam. A rápida transformação de uma educação/comunicação presencial numa comunicação mediatizada, levou a que os alunos, confinados em casa, passassem a não estar presencialmente no espaço escolar. Esta experiência do confinamento, que se iniciou em 12 de março de 2020, manteve os alunos até o final do ano letivo (junho de 2020) a assistir às aulas e a interagir, ainda que virtualmente, com os professores.

Uma questão essencial se fez sentir e tornou mais complexa a resposta à dificuldade que é a fratura digital (Castells, 2004, p. 301-302; Escola, 2015, p. 65-67), que destaca a efetiva desigualdade entre os comunicadores numa pretensa sociedade de informação e comunicação. Do início da pandemia "[...] até meados de maio, ou seja, até metade do $3^{\circ}$ período letivo, mais de metade dos docentes não tinha conseguido contactar com os seus alunos. Não estavam contactáveis pelos meios" (FENPROF, 2020, p. 6).

As possibilidades técnicas, disponibilidade de equipamento das instituições educativas, dos professores e alunos, foi o que garantiu o funcionamento regular das instituições educativas. Nos estados de emergência e de calamidade, assegurou-se, de uma forma global, que os alunos continuassem ligados à escola e aos seus professores, mas quer queiramos quer não, não permitiu uma experiência de comunicação que conservasse o ser humano integralmente, o ser humano enquanto ser encarnado. O ver, o ouvir estão disponíveis nas mensagens organizadas no espaço mediático pelas plataformas de ensino a distância, no entanto, os restantes sentidos encontram-se arredados no processo comunicacional, empobrecendo-o naturalmente. A dinâmica comunicacional da sala de aula, na interação professor - aluno, aluno - aluno, é transformada de uma forma radical pela situação do confinamento. Apesar do medo do contágio, das medidas de distância social, do uso da máscara, o regresso ao ensino presencial no ano letivo 2020-21 foi celebrado com grande entusiasmo pelos alunos portugueses. O que está em causa continua a ser a possibilidade de partilha dos mesmos espaços, da sala de aula como contexto de interação, de comunicação, de aprendizagem.

Mais do que nunca o contexto da pandemia foi um desafio para os educadores. Mais do que assegurar o cumprimento dos conteúdos programáticos, presentes nos programas disciplinares, impunha-se agora compreender contextos em que o aluno se encontrava e, simultaneamente, procurar espaços de verdadeiro encontro intersubjetivo, onde as aprendizagens se realizassem, mas sobretudo se apoiasse cada um a ultrapassar o sentimento de isolamento, medo, insegurança e desesperança. O domínio da relação e da comunicação intersubjetiva ganham uma nova centralidade, auxiliar a que construção da identidade dos alunos se fizesse num clima de cuidado (solicitude e disponibilidade), de liberdade, responsabilidade.

Alguns estudos realizados ainda durante o ano letivo anterior (2019-20) mostraram dados muito relevantes sobre o modo como as ins- 
tituições educativas, os professores e alunos encarregados de educação em Portugal responderam aos desafios provocados pela COVID-19, e ajudam-nos a pensar o presente e as implicações futuras para a comunicação educativa. O estudo de Silva e Ribeirinha (2020) ao inquirir sobre a forma como estava "[...] a decorrer o processo de EaD emergencial em Portugal em tempos de pandemia?" obteve alguma heterogeneidade nas respostas dos participantes no estudo, no entanto, o que se evidencia é a ausência de experiência de integração das tecnologias digitais. Apesar do esforço de modernização tecnológica das escolas por parte dos decisores políticos, que desde a década de 80 do século XX assumiram políticas educativas que apoiavam projetos no domínio da tecnologia educativa a serem desenvolvidos nas escolas portuguesas, a situação de pandemia pôs a descoberto algumas dimensões que não eram tão claras para a sociedade portuguesa: não havia uma experiência consolidada de integração das tecnologias digitais; o uso das Tecnologias Digitais da Informação e Comunicação não se revelaram uma prática generalizada nas escolas e que a inclusão digital dos alunos evidenciava deficits apreciáveis.

Sobre a integração curricular das tecnologias digitais de Informação e Comunicação (EaD), num estudo dirigido pelo investigador do Instituto Superior de Psicologia Aplicada, João Marôco (2020), onde se interrogaram, através de um inquérito online, entre os dias 5 e 25 de junho 2020, 4150 participantes (Educadores de infância, professores do ensino básico e secundário), obtiveram-se resultados sobre a frequência de utilização das ferramentas de EaD em sala de aula, antes da pandemia. Colocamos em destaque três resultados: 35\% dos professores declararam que nunca utilizaram uma plataforma de ensino a distância, seja Moodle, Classroom, MSTeams, ou qualquer outra; 46\% dos respondentes afirmaram nunca ter utilizado softwarelapps de avaliação digital (Moodle Quiz, Quizlet, QuizMaker, etc...), e 64\% dos inquiridos declararam nunca ter utilizado softwarelapps de aulas online (p.e. Zoom, Google Meet, MS Teams,...). Merecem ainda alguma atenção as respostas dos professores às perguntas sobre a utilização dos recursos de EaD durante a pandemia e a pergunta sobre as expectativas de utilizar recursos de EaD depois da pandemia.

Quanto a estas duas questões há uma proximidade entre os resultados, o que significa que os professores, apesar de não usarem com frequência os recursos de EaD nas suas práticas letivas, depois de terem passado pela necessidade da sua integração nas suas aulas por força da pandemia, demonstram abertura para continuar a fazer uso das mesmas no período pós-pandemia, é manifesta a disponibilidade para integrarem curricularmente os recursos de ensino EaD numa prática não emergencial.

No mesmo estudo, os professores foram inquiridos sobre a dificuldade na utilização dos recursos de EaD, os dados obtidos mostram que nunca se ultrapassou os $14 \%$ de professores que tivessem declarado como difícil o software /aplicações para aulas online, as plataformas de gestão de ensino e o software/aplicações de avaliação digital. Ao 
Comunicação Educativa

contrário, entre $68 \%$ e $60 \%$ consideraram como muito fácil o softwarel aplicações para aulas online (68\%), as plataformas de gestão de ensino (61\%) e o software/aplicações de avaliação digital (60\%).

Sobre a representação das vantagens ou desvantagens do ensino a distância por comparação com o ensino presencial, os resultados obtidos na investigação de Marôco são relevantes. Dos professores inquiridos sobre o que pensam em relação ao ensino a distância um em cada dois professores, cerca de $50 \%$ dos docentes consideram que o ensino a distância só deve ser usado em situação de emergência, e para consolidar conhecimentos e competências. No que diz respeito às preferências dos professores e alunos sobre a modalidade de ensino a distância ou ensino presencial, cerca de $75 \%$ dos professores consideram que nem os professores, nem os alunos têm preferência pelas aulas online. Mais de $80 \%$ dos professores consideram que não existem condições adequadas, do ponto de vista dos recursos de ensino (computador, software, acesso à internet), quer para as famílias (88\%), quer para as escolas (91\%) para o ensino a distância.

No que respeita à representação que os professores revelam da eficiência das aulas no ensino a distância para quem ensina e para quem aprende, os resultados são muito claros. Sessenta e cinco por cento dos professores discordam ou discordam completamente que o ensino a distância torna as aulas mais eficientes para quem aprende e $61 \%$ dos professores discordam ou discordam completamente que o ensino a distância torna as aulas mais eficientes para quem ensina. Esta conclusão atesta, de forma inequívoca, a importância que os professores portugueses atribuem às aulas presenciais.

Convém, no entanto, incluir na discussão a problemática da formação docente. O cenário em que os professores tiveram que agir era radicalmente diferente que qualquer cenário de formação tivesse pensado. A aposta na formação em recursos EaD, nas plataformas de ensino a distância ou mesmo o software de avaliação em EaD havia sido muito reduzida ou quase inexistente. As dificuldades tornam-se mais significativas se tivermos em conta que os professores portugueses são um grupo envelhecido e que o sistema não conseguiu renovar os quadros (FENPROF, 2020, p. 4).

A questão da formação para o uso de recursos de EaD na investigação de Marôco (2020) revela que quatro quintos dos professores declara que discordam ou discordam completamente que a maioria dos professores tem formação suficiente para o ensino a distância. Há um dado importante que ressalta no estudo. Apesar de $80 \%$ dos professores não possuir formação suficiente, confrontados com a necessidade de fazer uso desses recursos, a maioria dos professores, ainda que de forma autodidata, soube encontrar soluções para as dificuldades. Este dado sobre a formação para o uso de recursos de $\mathrm{EaD}$, articulado com os dados referentes à menor dificuldade que na utilização de recursos de EaD ajuda a compreender a capacidade de resposta dada pelos professores no período do confinamento. Importa interpretar com alguma reserva estes dados, uma vez que nada é dito sobre as transformações 
nas metodologias de ensino. Dito de outro modo, não é seguro que a integração dos recurso de EaD nas práticas docentes tenha sido acompanhada de uma mudança efetiva nas práticas e nas metodologias. Cabero Almenara (2020) tem discutido com acuidade esta questão na Espanha, alertando para o que considera ser uma reduzida competência digital demonstrada por alguns docentes na incorporação educativa das tecnologias digitais.

Há um dado muito relevante sobre o qual importa refletir. As escolas portuguesas iniciaram as aulas do terceiro período, após o período de interrupção letiva das férias da Páscoa, no mês de abril de 2020. Aquilo a que se assistiu nas instituições educativas do país, foi a substituição das aulas presenciais por aulas lecionadas através de plataformas de ensino a distância, opção e orientação que se manteve inalterada até ao fim do ano letivo.

O presente ano letivo iniciou-se na segunda semana de setembro, entre os dias 15 e 17 de setembro, mas com uma orientação muito diferente da que tinha vigorado no terceiro período do ano anterior. Apesar dos números da pandemia não darem sinais de abrandamento e de se suspeitar que o país seria atingido por uma segunda vaga do COVID-19, a partir do mês de outubro, constatamos uma decisão diferente: o governo português, o ministério da educação querem que os alunos regressem ao regime presencial combinado, eventualmente, em alguns momentos, com o ensino virtual, isto é, um regime misto. Neste sentido as conclusões do estudo de Silva e Ribeirinha (2020) concretizouse, uma vez que estes investigadores defendiam que uma das lições da primeira fase da pandemia seria que o b-learning passaria a ser o novo normal na educação escolar. Apesar da avaliação feita sobre o funcionamento apresentar resultados muito satisfatórios durante o período de confinamento dos alunos, a decisão do Ministério da Educação foi pela manutenção do regime presencial nas Escolas, independentemente de se continuar a assistir ao crescimento do número de infetados e de focos de contágio, o que sugere uma menorização do ensino a distância. Cabero Almenara e Valencia-Ortiz (2020, p. 222-223) discutem a mesma questão na Espanha e consideram que a opção pelo presencial, atendendo ao imaginário social e académico acabou por apesentar a formação virtual, quando comparada com a presencial, como uma formação de segunda categoria. Para os autores (Cabero Almenara; Valencia-Ortiz, 2020, p. 222-223), a única coisa que pode estar em causa é a qualidade. As preferências por um tipo ou outro de formação decorrem de critérios/varáveis com que se lida. As preferências por uma ou outra formação têm que ver com a idade dos estudantes, conteúdos a transmitir ou mesmo as competências que se deseja alcançar.

A exigência de manutenção da distância social nos espaços, o uso obrigatório de máscara, a organização dos espaços circum-escolares e dos tempos de recreio para evitar que os alunos se misturem indiscriminadamente e se torne mais complexa a identificação das cadeias de contacto. Em Portugal há a apologia do regresso ao novo normal (Castells, 2020), o que confirma a tendência europeia de recusar o confina- 
Comunicação Educativa

mento das populações ou o encerramento das escolas e a sua entrada num sistema híbrido, para estar em conformidade com o mundo, pois como Castells (2020) prevê "O nosso mundo é será necessariamente híbrido, feito de realidade carnal e realidade virtual".

Cabero Almenara e Valencia-Ortiz (2020, p. 219) alertam para o perigo de se fazer no virtual o mesmo que se fazia no presencial, “[...] abusando de videoconferências, com o erro adicional de não ponderar o volume de informação e atividades que transmitiam e exigiam aos estudantes" (Cabero Almenara, 2020, p. 2). Tratando-se de contextos diferenciados as estratégias de comunicação variam exigindo que professores e alunos recorram a habilidades e competências diferentes:

Em grande medida o que que se tentou foi replicar no virtual o que se havia feito antes no presencial, sem refletir que se trata de dois contextos diferentes que requerem tanto ao docente como aos alunos mobilizar habilidades e competências diferentes (Cabero Almenara; ValenciaOrtiz, 2020, p. 219).

\section{Conclusões}

Neste artigo, num primeiro momento procurámos refletir sobre a noção de comunicação educativa, estabelecendo o que designei como os quatro axiomas da comunicação educativa, discutindo a sua importância na relação com as tecnologias na educação e com a tecnologia educativa. A evolução da comunicação (Cloutier, 2001) estabelece uma relação entre a comunicação no contexto educativo e os dispositivos técnicos que se foram inventando e o modo como se integraram na escola, transformando a comunicação educativa. Nos quatro axiomas buscamos evidenciar quatro ideias centrais para responder a uma civilização cada vez mais tecnológica. Por muito que se multipliquem as ferramentas tecnológicas e que estas invadam os vários domínios da sociedade, se instalem e condicionem o quotidiano dos cidadãos, a problemática comunicação educativa impõe a necessidade de inscrever a comunicação no âmago da ação educativa. Assim, defendemos como primeiro axioma que não há educação sem comunicação; o segundo axioma discute a estreita relação entre a existência e a educação, mostrando que a educação tem a mesma extensão que a noção de existência. A condição humana marcada pelo inacabamento, inconclusão e insatisfação, tornam o homem um sujeito de busca, aprendendo desde o nascimento até morte, estabelecendo como segundo axioma a relação entre existir e educar(se).

Ainda que a escola tenha uma preocupação com a comunicação objetiva, com o cumprimento estrito dos programas oficiais, com a transmissão da informação, e naturalmente o sucesso na aprendizagem, a comunicação educativa vai para além desta exigência defendo no seu terceiro axioma que a comunicação objetiva, formativa, instrutiva deve abrir espaço a uma relação eu-tu, a uma comunicação intersub- 
Escola

jetiva, onde verdadeiramente se encontra a pessoa de cada aluno com a pessoa do próprio professor.

O quarto axioma reconhece que os meios e recursos de ensino e, de forma muito especial, os recursos digitais sejam integrados, criteriosamente, como mediações nos processos de comunicação e, ao mesmo tempo, como facilitadores na (co)construção do conhecimento e na formação da identidade dos alunos. A história das tecnologias na educação, da tecnologia educativa e da comunicação mostram um diálogo estreito com a comunicação educativa.

$\mathrm{O}$ contexto da pandemia trouxe enormes desafios à sociedade e à escola, recordando-nos, de forma definitiva, que nada será igual depois da experiência que o mundo inteiro fez da pandemia do COVID-19. Partindo de estudos muito recentes, discutimos algumas das questões que têm e terão implicações na concepção de comunicação educativa que defendemos. A exigência do confinamento da população portuguesa em geral e dos alunos e professores, em particular, estabeleceu um quadro de exigências e proporcionou uma experiência absolutamente única, onde todos foram convidados a aprenderem a viver no que Castells (2020) designou como novo normal. Uma das cinco lições para a educação no período pós-pandemia, como escrevem Silva e Ribeirinha (2020), foi “[...] tornar $o$ b-learning como o novo normal na educação escolar".

Ainda que os professores e alunos não tivessem tido formação específica para a utilização de recursos de $\mathrm{EaD}$, foram capazes de o fazer num período de tempo muito curto. De repente a utilização de plataformas de ensino e distância configurava-se como única possibilidade de assegurar a continuidade das atividades letivas e de permitir o contato e relação entre os alunos e os docentes, impedidos de assistir presencialmente às aulas. A necessidade de utilização de recursos EaD "[...] aprofundou dimensão digital/online das escolas e da sociedade" (Silva; Ribeirinha, 2020). Esta constatação do estudo de (Silva; Ribeirinha, 2020) é , seguramente, uma das marcas mais relevantes decorrentes da pandemia. Vai para além dela, pois as aprendizagens que professores e alunos realizaram sobre a utilização de recursos EaD mostraram possibilidades que num ensino híbrido poderia e deveria ser aproveitado. $\mathrm{O}$ contexto pandêmico, as indicações da Direção Geral de Saúde e as restrições impostas pelo governo português ao funcionamento das escolas permitiram identificar potencialidades dos dispositivos tecnológicos como mediações nos processos comunicacionais, mas, ao mesmo tempo, devolveram a consciência a todos do lugar incontornável da comunicação intersubjetiva na comunicação educativa, da "[...] importância vital da escola - presencial” (Silva; Ribeirinha, 2020).

As dificuldades criadas pela pandemia desvelaram uma realidade um pouco esquecida do país, ou pelo menos da qual não se tinha uma consciência tão clara. A promessa da modernidade no progresso contínuo esbarra com situações de incumprimento, de não realização. A promessa de que a tecnologia criaria condições para um acesso generalizado e mais democrático a todos os bens disponibilizados pela revolução informática esmorece diante das desigualdades efetivas en- 
tre continentes, entre países, entre regiões. Em Portugal, constatou-se a existência de uma efetiva fratura digital. A percentagem de cidadãos sem computador em casa, sem acesso à internet, com poucas competências digitais, que não faziam utilização frequente do computador, que não possuem computadores em número suficiente para assegurar o teletrabalho dos pais e o acesso às aulas dos seus filhos tornou mais difícil a resposta. No entanto, com o esforço de todos, acabou-se por encontrar soluções para ajudar a minorar a fratura digital. Em certa medida, como defendem Silva e Ribeirinha (2020), a pandemia acabou por tornar clara a fratura digital e, ao mesmo tempo, desencadeou no interior da sociedade a busca de soluções que garantissem a inclusão digital e a transição digital. A comunicação educativa teve, no período do confinamento, um conjunto incontornável de desafios que com o envolvimento de todos permitiu encontrar respostas que vieram reforçar o reconhecimento do papel decisivo dos professores e da cooperação entre estes, de responder a um contexto de emergência, preparando-se para a situação que se vive nas instituições de ensino em Portugal, que é a da competência para articular a comunicação presencial e a comunicação a distância.

Recebido em 1 de outubro de 2020 Aprovado em 12 de novembro de 2020

\section{Referências}

BELL, Daniel. The Coming of Post-Industrial Society: a venture in social forecasting. New York: Penguin, 1976.

BERTALANFFY, Ludwig. Perspetivas en la Teoría General de Sistemas. Madrid: Alianza Editorial, 1986.

BUBER, Martin. Eu e Tu. Águeda: Paulinas Editora, 2014.

CABERO ALMENARA, Julio. Aprendiendo del Tiempo de la COVID-19. Revista Eletrónica Educare, Heredia, v. 24, Suplemento Especial, p. 1-3, 2020.

CABERO ALMENARA, Julio; VALENCIA-ORTIZ, Rubicelia. Y el COVID-19 Transformó al Sistema Educativo: reflexiones y experiencias por aprender. Internacional Journal of Educational Research and Innovation, v. 15, p. 217-227, 2020.

CASTELLS, Manuel. A Galáxia Internet. Lisboa: Fundação Calouste Gulbenkian, 2004.

CASTELLS, Manuel. O Digital é o Novo Normal. In: FRONTEIRAS DO PENSAMENTO, 2020. Anais... 26 de maio de 2020. Disponível em: <https://www.fronteiras.com/artigos/o-digital-e-o-novo-normal>. Acesso em: 1 set. 2020.

CLOUTIER, Jean. A Era de Emerec ou a Comunicação Audio-Scripto-Visual na Hora dos Self-Media. Lisboa: Instituto de Tecnologia Educativa, 1975.

CLOUTIER, Jean. Petit Traité de Communication. EMEREC à l'heure des tecnhologies numériques. Montreal: Les éditions Carte Blanche, 2001.

COSTA, Fernando Albuquerque. Educational Technologies: analysis of Master dissertations carried out in Portugal. Sísifo. Educational Sciences Journal, n. 3, p. 7-24, May/Aug. 2007. 
CUBAN, Larry. Teachers and Machines - the classroom use of technology since 1920. New York: Teachers College Press, Columbia University, 1986.

ECHEVERRÍA, Javier. Telépolis. Barcelona: Destino, 1994.

ESCOLA, Joaquim. Habitar na Tecnopolis: Espaço Público, Democracia e Direitos Humanos numa Civilização Tecnológica. Utopia y Praxis Latinoamericana: Revista Internacional de filosofia iberoamericana y teoria social, Maracaibo, v. 20, n. 70, p. 59-70, 2015.

FENPROF. Federação Nacional dos Professores. O ensino a distância (EaD). As perceções e a(s) palavra(s)dos professores. 2020. Disponível em: <https://www. fenprof.pt/Download/FENPROF/SM_Doc/Mid_115/Doc_12667/Anexos/ED__a_percecao_dos_professores.pdf $>$. Acesso em: 30 jun. 2020.

FERMOSO, Paciano. Teoria de la Educación. Una Interpretación Antropológica. Barcelona: Ediciones CEAC, 1985.

FREIRE, Paulo. Uma Educação para a Liberdade. Porto: Textos Marginais, 1974.

FREIRE, Paulo. Educação como Prática da Liberdade. Rio de Janeiro: Paz e Terra, 1984.

FREIRE, Paulo. Extensão ou Comunicação. Rio de Janeiro: Paz e Terra, 1988.

FREIRE, Paulo. Pedagogia do Oprimido. Rio de Janeiro: Paz e Terra, 2007.

JASPERS, Karl. Philosophie. Paris: Springer Verlag, 1989.

LYOTARD, Jean-François. O Pós-Moderno Explicado às Crianças. Lisboa: Publicações Dom Quixote, 1987.

LYOTARD, Jean-François. A Condição Pós-Moderna. Lisboa: Gradiva, 1989.

MARCEL, Gabriel. Journal Methaphysique. Paris: Éditions Gallimard, 1927.

MARCEL, Gabriel. Le Mystère de L'Être. Vol. 1. Paris: Aubier Éditions Montaigne, 1950.

MARÔCO, João. Experiências de ensino a distância em tempos de pandemia. 2020. Disponível em: <https://somossolucao.pt/2020/08/31/o-que-nos-dizemos-dados/?fbclid=IwAR0tZWKtVPjMkmWrDQmPVTpBvDzF6Oemk7OBT3W4HoQDNchW8bwPiLxn8w>. Acesso em: 1 jul. 2020.

MOUNIER, Emmanuel. O Personalismo. Lisboa: Edições Texto \& Grafia Lda, 2010.

POSTMAN, Neil. Tecnopolia. Quando a cultura se rende à tecnologia. Lisboa: Difusão Editorial, 1994.

POSTMAN, Neil. O Fim da Educação. Redefinindo o valor da escola. Lisboa: Relógio d'Água, 2002.

REDONDO, Emílio. Educación y Comunicación. Barcelona: Editorial Ariel, 1999.

SHANNON, Claude Elwood. A Mathematical Theory of Communication. Bell System Technical Journal, v. 27, n. 3, p. 379-423, jul. 1948.

SILVA, Bento; RIBEIRINHA, Teresa. Cinco Lições para a Educação Escolar Depois da COVID. Interfaces Científicas, Aracaju, v. 10, n. 1, p. 194-210, 2020.

SKINNER, Burrhus Frederic. La Revolution Scientifique de l'Enseignement. 5. ed. Bruxelles: Pierre Mandaga Éditeur, 1969. [1968]

VATTIMO, Gianni. A Sociedade Transparente. Lisboa: Edições 70, 1991.

WATZLAWICK, Paul; BEAVIN, Janet; JACKSON, Don. Pragmatics of Human Communication: a study of interactional patterns, pathologies and paradoxes. New York: W. W. Norton \& Company, 1967. 
Joaquim José Jacinto Escola licenciou-se em Filosofia na Universidade de Coimbra, Portugal no ano letivo de 1986- 87. Obteve o grau de licenciado em Filosofia- ramo de formação profissional no ano letivo de 1990- 91 na Universidade de Coimbra. Obteve o grau de Mestre em Filosofia Contemporânea, Universidade de Coimbra, Portugal, em 1993. O Doutoramento, em Ciências da Educação foi realizado na Universidade de Trás-os-Montes e Alto Douro, Portugal, em 2003. Atualmente é Professor Auxiliar com nomeação definitiva no Departamento de Educação e Psicologia, Escola de Ciências Humanas e Sociais, UTAD, desde 2008.

ORCID: http://orcid.org/0000-0002-6676-6928

E-mail: jescola@utad.pt

Editora-responsável: Carla Vasques

Este é um artigo de acesso aberto distribuído sob os termos de uma Licença Creative Commons Atribuição 4.0 Internacional. Disponível em: <http:// creativecommons.org/licenses/by/4.0>. 